\title{
Identification of Polyethylene Terephthalate (PET) Polymer Using X-ray Diffractogarm Method: Part 1
}

\author{
Ibe Kevin Eiogu ${ }^{1,2,3, *}$, Uche Ibeneme ${ }^{1,3}$, Olukemi Mosunmade Aiyejagbara ${ }^{1}$ \\ ${ }^{1}$ Department of Polymer Technology, Nigerian Institute of Leather and Science Technology, Zaria, Nigeria \\ ${ }^{2}$ Department of Research, Development, Process and Operations, Nigerian Institute of Leather and Science Technology, Zaria, Nigeria \\ ${ }^{3}$ Department of Chemistry, Ahmadu Bello University, Zaria, Nigeria
}

Email address:

kevin.edu.research@gmail.com (I. K. Eiogu)

${ }^{*}$ Corresponding author

\section{To cite this article:}

Ibe Kevin Eiogu, Uche Ibeneme, Olukemi Mosunmade Aiyejagbara. Identification of Polyethylene Terephthalate (PET) Polymer Using Xray Diffractogarm Method: Part 1. American Journal of Nano Research and Applications. Vol. 8, No. 4, 2020, pp. 58-62.

doi: $10.11648 /$ j.nano.20200804.11

Received: December 5, 2020; Accepted: December 14, 2020; Published: January 30, 2021

\begin{abstract}
X-Ray Diffraction XRD method was used to identify six PET polymers samples collected from different dump sites around the city, they were washed crushed and characterised and x-ray diffraction (XRD) analysis was carried out on the samples for identification and the results were compared with literature. The diffractogram finger print patterns generated by the samples were studied and informed discussions were made. The XRD analysis showed that six samples of the PET polymer studied showed triclinic crystalline structure, the samples showed an average specific gravity of 1.33 and their $2 \theta_{3}$ Max Peaks fell within 24-27. In addition the ACD $(\AA)$ was $\approx 0.5, \approx 4.99, \approx 4.99, \approx 4.98, \approx 4.97$ and 4.96 for PET polymer samples A, B, C, D, $\mathrm{E}$ and $\mathrm{F}$ respectively. The FWHM was $0.5,0.51,0.52,0.52,0.53$, and 0.54 for PET polymer samples $\mathrm{A}, \mathrm{B}, \mathrm{C}, \mathrm{D}, \mathrm{E}$ and $\mathrm{F}$ respectively. These results were consistent with the studies of previous researchers. While the XRD analysis is a good tool that can be used to identify the PET polymers it cannot however, be able to differentiate between PET polymers that are identically similar and produced from different sources, more characterization method may still have to be deployed to overcome these challenges.
\end{abstract}

Keywords: $2 \theta$ Max Peak, Average Crystalline Dimension (ACD) $\AA$, Percent (\%) Crystallinity, PET Identification, X-ray Difraction (XRD) Analysis

\section{Introduction}

Identifying of polymers is a very important aspect in polymer science and engineering technology and more effective and efficient method of identifying polymers is always an interest to polymer scientists all over the world because of the very importance roles polymers plays in every aspect of human endeavor. These critical roles of polymers in the global community be it domestic or industrial have contributed immensely to the increasing presence of polymers in the world today. This also has a direct impact on the increasing waste plastics in the world today creating environmental challenges [1]. One of such characterization technique is the XRD analysis. X-ray diffraction analysis is one of the effective ways of investigating and characterizing atomic and molecular structures of polymers. X-ray diffraction not only provides a platform for critical analysis and interrogation of the polymers but also provides an invaluable insight into conformational and configurational orientation of the polymers, most expecially during mechanical analysis when stretching, orientation, slippage, bond breaking and formation are involved. Employing X-ray Diffraction as a non- ddestructive technique in identifying the physico-chemical properties of polymers cannot be over emphasized [2].

The x-ray patterns produced in the diffractogram are unique for each crystalline polymer sample studied; they are independently produced of each other; the diffractogram pattern intensity is directly proportional to the phase abundance [3]. The polymer can thus be characterized qualitatively and quantitatively on their aggregate phase 
composition by x-ray powder diffraction. The obtained peaks for the materials in the diffractogram were indexed and matched with the standard Joint Committee on Powder Diffraction Standards (JCPDS) and the main phases identified. The crystallinities of these samples as determined by Farrow and Preston procedure [13, 14], in which radial scans for the randomized sample and for the amorphous standard are required for calculation of percent crystallinity.

$$
X c=\frac{l_{c}}{l_{c}+l_{a}}
$$

Where, $X c$ is degree of crystallinity, $l c$ and $l a$ are the intensities of the crystalline and the amorphous region peaks respectively [5].

The full-width at half-maximum (FWHM) is sensitive to the variation in microstructure and stress-strain accumulation in the material as indicated in the XRD peak profiles. Many researchers have successfully attempted the use of FWHM in different manufacturing processes [6]. A handful of researchers have identified various material properties via the FWHM of XRD peaks and it was noted that disorderliness and faults widen the XRD peaks [7]. Variations such as Increase in hardness and density of point defects affect the crystallinity and grain boundary mobility, which in turns causes other variations such as a linear increase in the FWHM of XRD peak [6]. Application of mechanical stress in a polymer causes an increase in the FWHM while removal of mechanical stress decreases FWHM [6]. The Scherrer equation can be used as an indication of the size of the crystallite of the polymer under study.

$$
\mathrm{D}=\frac{K \lambda}{\beta \cos \theta}
$$

where, $\mathrm{D}$ is the crystallite size, $\mathrm{K}$ is Scherrer constant which changes with crystallite shape but approximately $0.94, \lambda$ is the wavelength of source radiation and $\beta$ is full-width at half maximum (FWHM) of the peak, in radians and $\theta$ is the Bragg's angle [8]. The crystallite size is calculated using the Scherrer formula for the prominent peaks for the polymers in the diffraction pattern for the material as indicated in the diffractogram.

Crystallinity and grain boundry mobility is affected by Increase in hardness and density, which in turn creates a linear increase in the FWHM of XRD peak. It will be observed during the cause of the study that the PET polymer samples analysed showed a diffractogram patterns that exhibited major characteristic crystalline peaks at the scattering angles $2 \theta$ which corresponds to the various reflection planes. This clearly indicates the type of crystals and crystalline structures that are retained by the material [6]. Crystalline peaks at the $2 \theta$ axis in the XRD diffractogram, these crystalline maximum peaks may be two or more and remain extremely crucial finger prints in the identification of the polymer materials under study. The aim of this study is to examine the viability of using XRD as a viable tool in the identification and characterization of waste PET polymers and also in the viability in utilising XRD analysis in forensic analysis of polymers.

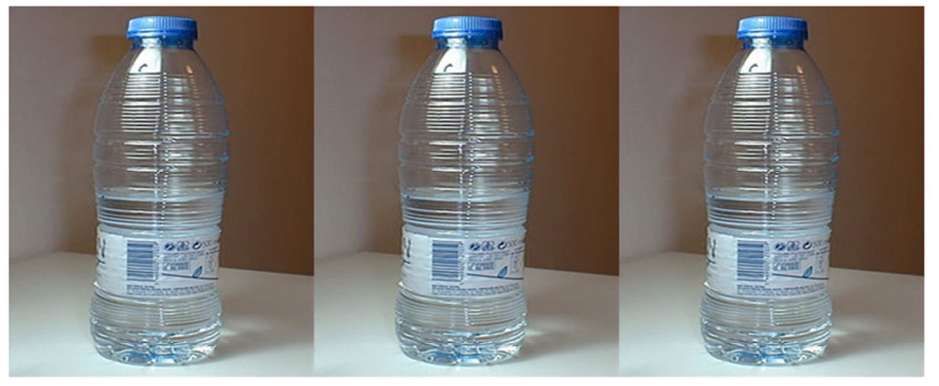

(a)

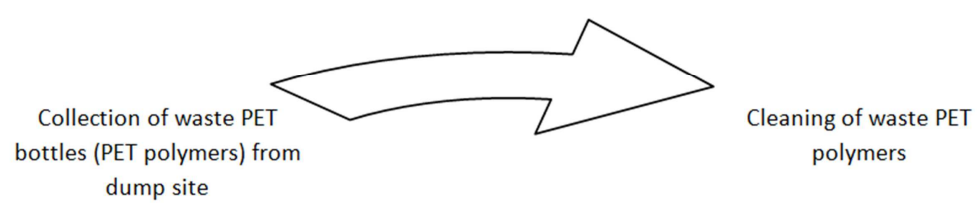

Characterisation of PET polymers

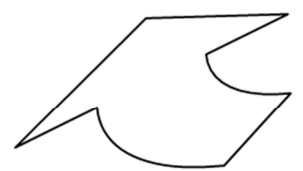

Washing of PET polymers

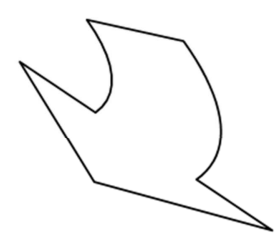

(b).

Figure 1. (a) Waste PET Polymer bottles collected at dump site; (b) Diagrammatic representation of methodology. 


\section{Research Methodology}

\subsection{Materials}

The Polyethylenetrephthalate (PET) polymers were predominantly waste plastic bottles obtained from dump site around the city.

\subsection{Method}

The waste PET polymer bottles that had been collected were cleaned and the cover and its labels were removed, they were then washed and allowed to dry in the sun. It wasthen crushed to a mesh size of $200 \mathrm{~mm}$ using plastic crushing equipment (NPCP-50J) provided by Processing Laboratory, Department of Polymer Technology, Nigerian Institute of Leather and Science Technology (NILEST). Physicomechanical properties of the PET polymer were carried out as indicated in Table 1.

Table 1. Physico-mechanical Properties of PET polymer.

\begin{tabular}{|c|c|c|c|c|c|c|}
\hline \multirow{2}{*}{ Properties } & \multicolumn{6}{|c|}{ PET Polymer samples } \\
\hline & $\mathbf{A}$ & B & $\mathbf{C}$ & D & $\mathbf{E}$ & $\mathbf{F}$ \\
\hline Specific Gravity [9] & 1.38 & 1.37 & 1.37 & 1.36 & 1.35 & 1.34 \\
\hline Water Absorption \% [9] & 0.1 & 0.1 & 0.1 & 0.1 & 0.1 & 0.1 \\
\hline Loose Bulk Density $\left(\mathrm{Kg} / \mathrm{m}^{3}\right)[10]$ & 520 & 519 & 519 & 518 & 517 & 516 \\
\hline Compacted Bulk Density $\left(\mathrm{Kg} / \mathrm{m}^{3}\right)[10]$ & 638.98 & 638.78 & 638.68 & 637.92 & 637.88 & 637.79 \\
\hline Compaction Factor [10] & 0.81433 & 0.81248 & 0.81261 & 0.81201 & 0.81049 & 0.80904 \\
\hline$\%$ Void $[10]$ & 50.29 & 50.10 & 50.20 & 50.12 & 50.15 & 50.16 \\
\hline $\operatorname{MFI}(\mathrm{g} / 10 \mathrm{mins})[12,25]$ & 27.0 & 26.0 & 26.1 & 25.1 & 25.0 & 24.9 \\
\hline
\end{tabular}

\subsection{X-ray Diffraction Analysis}

$\mathrm{X}$-ray diffraction analysis was used for the characterisation of PET polymer using a JOEL JDX equipment (XRD-3530) provided by Nigerian Geological Survey Agency, Barnawa in Kaduna State. The samples were ball milled into smaller sizes and sieved using the $50 \mu \mathrm{m}$ sieve. The sieved particles were then loaded into the sample holder. The sample holder was loaded into the X-ray Diffraction equipment. The sample holder was rotated as it was bombarded with X-ray and the detector picked up the diffracted ray. The angles of the incident and diffracted ray were kept constant as the sample was rotated by a goniometer. When the geometry of the incident X-rays impinging the sample satisfied the Bragg equation, constructive interference and a peak in intensity occurred. A detector records and processes this X-ray signals and cross referenced with patterns on the computer data base to obtain the phases for the spectra obtained. When the phases have been identified, it was converted to a count rate which was then output to a device such as a printer or a computer monitor. XRD data were collected at room temperature using $\mathrm{Cu}-\mathrm{K} \alpha$ radiation shown in equation (3) below

$$
\left(\lambda=1.5406 \times 10^{-10} \mathrm{~m}\right)
$$

Where $\lambda$ is the wavelength of source radiation.

It was operated in the reflection geometry $(\theta / 2 \theta)$. Data were recorded from $10 \circ$ to $60 \circ(2 \theta)$ with a step-size of 0.02 . The X-ray tube was operated at $40 \mathrm{kV}$ and $40 \mathrm{~mA}$.

\section{Results and Discussion}

The XRD diffractogram was obtained from six different PET Polymer samples and were extensively investigated. One of the diffractogram generated during the study is indicated in Figure 2 below. The diffractogram obtained from the remaining five PET polymer samples were similar with Figure 2 and also bore similar finger print form with the ones obtained from previous research [4]. All PET polymer samples crystallised in the triclinic system with a crystallinity of $75 \%, 74 \%, 74 \%, 73 \%, 70 \%$ and $69 \%$ for samples $\mathrm{A}, \mathrm{B}, \mathrm{C}$, $\mathrm{D}, \mathrm{E}$ and $\mathrm{F}$ respectively as indicated in Table 2, this high crystalline content is noticed because the polar groups in the molecules are held strongly together in strong van der waals forces having hydrophobic interactions with no loss of strength on wetting. Similar study was also seen in the study of Devi et al., [13] where the eight PET fibre under study were all triclinic in crystal structure. The closely packed crystalline structure in the PET polymer samples clearly influenced the density which was recorded as $1.38 \mathrm{~g} / \mathrm{cm}^{3}$, $1.37,1.36,1.35,1.35,1.34$ in samples A, B, C, D, E and F respectively. The maximum $2 \theta$ peak intensity for the WPET were $25.80,24.8,24.6,23.8,23.6$ and 21.26 respectively. This values followed the same trend with the work of Singh et al., [4] who showed the various maximum $2 \theta$ peak intensities of PET polymers fell within $24^{\circ}$ to $27^{\circ}$ (for $2 \theta_{3}$ Max Peaks) as indicated in Table 2. The results are similar to that of Singh et al., [4] who showed that the peak angles of the eight PET fibre samples under study as indicated by their diffractogram fingerprints where $\left(2 \theta_{3}\right.$ Max Peaks ) were between $25.4^{\circ}$ to $26^{\circ}$. The PET polymers had Average Crystalline Dimension (ACD) of $\approx 5.0,4.99,4.99,4.98,4.97$ and 4.96 for samples A, B, C, D and E and F respectively which was a major reason for the dense crystalline crystals experienced in the samples as indicated in this study. The FWHM which is also an indication of the level of large crystalline content in the PET samples [4, 13, 14], the FWHM of $0.5,0.51,0.52,0.52,0.53$ and 0.54 respectively were observed for samples A, B, C, D, E and F respectively. The results are indicative of the fact that the prolonged 
exposure of the PET polymer bottles in the dump site had little or no effect on the crystalline structure and densities of the PET polymers showing their high resistance to environmental degradation [15-17]. In addition the manufacturing processes for each of the PET polymers could be sufficiently different from one another and these variations in processibility could lead to the differences in the crystallinity as indicated in the result which did not follow any particular trends, thus the XRD analysis may not be able to differentiate between PET polymers that are identically similar and produced from different sources, more characterization method may still have to be adopted to overcome these challenges. This was clearly shown in the study of Singh et al., [4, 18] where Infrared(IR) spectroscopy, Differential scanning calorimetry (DSC), Laser-induced breakdown spectroscopy (LIBS) analysis Fourier Transform Infra Red (FT-IR) were used in collaboration with XRD analysis [19-24].

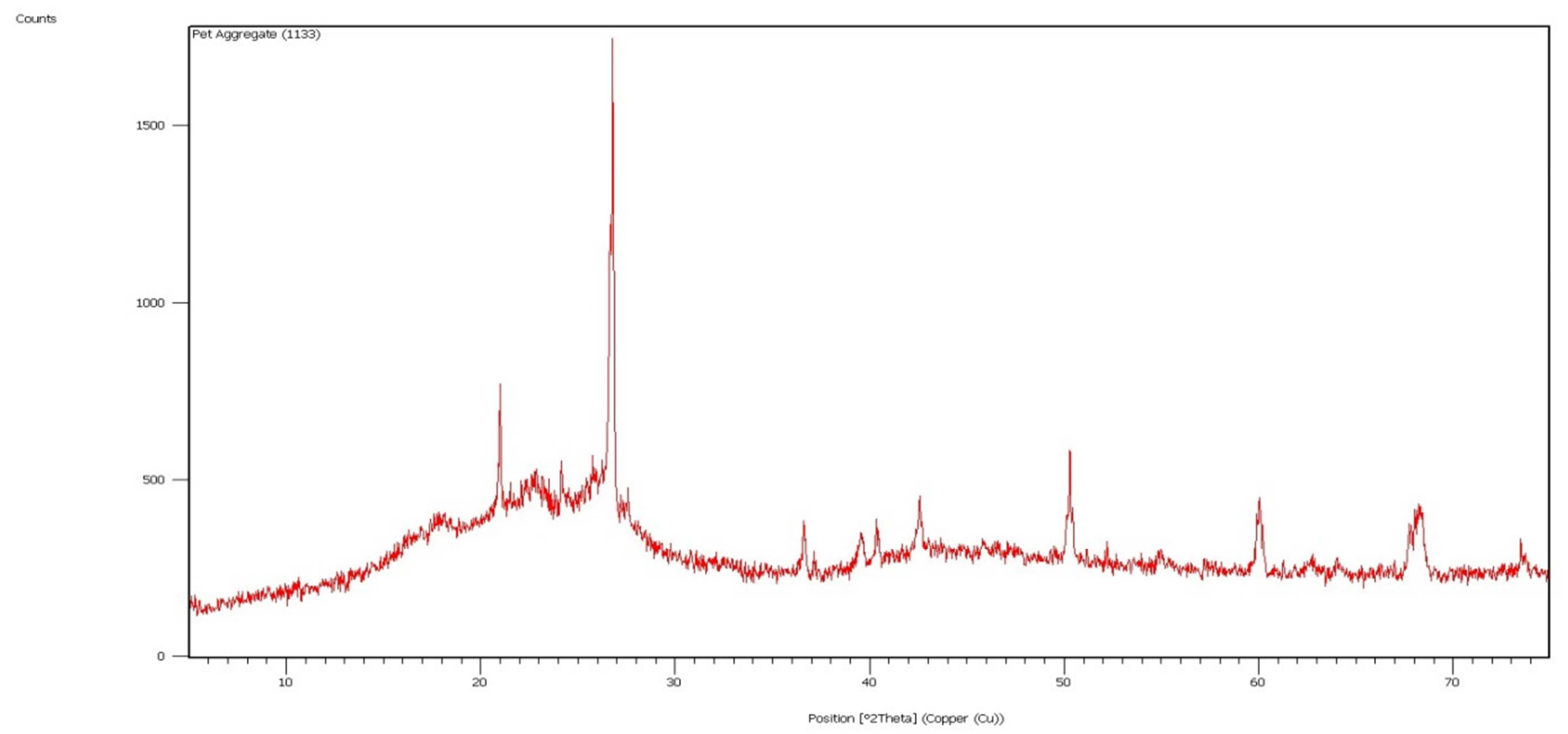

Figure 2. X-Ray Diffractogram for PET Polymer Sample.

Table 2. XRD Analysis of PET Polymers.

\begin{tabular}{lllllll}
\hline \multirow{2}{*}{ Properties } & \multicolumn{2}{l}{ Phase Composition of PET Samples } & & & \\
\cline { 2 - 7 } & A & B & C & D & E & F \\
\hline Crystalline Structure & Triclinic & Triclinic & Triclinic & Triclinic & Triclinic & Triclinic \\
\hline \% Crystallinity & 75 & 74 & 74 & 73 & 70 & 69 \\
ACD $(\AA)$ & $\approx 5.0$ & $\approx 4.99$ & $\approx 4.99$ & $\approx 4.98$ & $\approx 4.97$ & $\approx 4.96$ \\
FWHM & 0.50 & 0.51 & 0.51 & 0.52 & 0.53 & 0.54 \\
$2 \theta_{1}$ Max Peak & 20.50 & 20.40 & 20.40 & 20.30 & 20.10 & 20.00 \\
$2 \theta_{2}$ Max Peak & 23.00 & 22.20 & 22.10 & 21.98 & 21.80 & 21.60 \\
$2 \theta_{3}$ Max Peak & 25.80 & 24.80 & 24.70 & 24.50 & 24.20 & 2.00 \\
$\rho\left(\mathrm{g} / \mathrm{cm}^{3}\right)$ & 1.38 & 1.37 & 1.37 & 1.36 & 1.35 & 1.34 \\
\hline
\end{tabular}

\section{Conclusion}

The utilization of XRD analysis has been carried out for different PET polymers and characterisations and comparison were made with the works of previous researchers and academics that have made meaningful contribution to this area of study. Even though the XRD diffraction technique is a very effective method to be employed in the identification of PET polymer by employing very good comparison in the finger prints in the diffractograms generated and can also differentiate between polymer types in plastic wastes, it remains however, not sufficient enough to identify individual differences in the polymers such as manufacturing source, shelf life, rate of aging, relationships between crystallinity and mechanical properties, thermal histories, functional groups, elemental components Other characterisation techniques such as Differential scanning calorimetry, Laserinduced breakdown spectroscopy (LIBS) analysis, Fourier Transform Infrared(FTIR), Dynamic mechanical analysis and thermo gravimetric analysis (TGA) may have to be adopted in a synergistic way to overcome these challenges.

\section{References}

[1] J. Scheirs, and W. Kaminsky, "Feedstock recycling and pyrolysis of waste plastics". Converting Waste Plastics into Diesel and Other Fuels. John, Wiley \& Sons, Ltd., UK, 2006; 363-380. 
[2] S. R. Ahmad, A new technology for automatic identification and sorting of plastics for recycling. Environ. Technol, vol. 25, pp. 1143-1149, 2004, DOI: 10.1080/0959332508618380.

[3] R. D. Dauben, and C. Bunn, "The crystal structure of polyethylene terephthalate". pg. 531- 542, 2018, Retrieved $\begin{array}{llll}\text { December } & 3 r d, & 2020 & \text { from }\end{array}$ http://rspa.royalsocietypublishing.org/

[4] D. Singh, K. H. Malik, K. C. Gupta, and V. Singh, "X-ray diffraction studies for identification of polyethylene terephthalate fibres". Indian Journal of Science and Technology, vol. 10, no. 2, pp. 1-4, 2007, DOI: 10.17485/ijst/2017/v10i17/110232.

[5] M. A. Shuaibu, and P. A. Mamaza, "Characterisation of polypropylene filled composite using scanning electron microscopy and x-ray diffraction". International Journal of Innovative Research and Development, vol. 5, no 3, pp. 130$135,2016$.

[6] R. Jadhav, and N. C. Debnath, "Computation of X-ray powder diffraction of cement components and its application to phase analysis and hydration performance of OPC cement". Bulletin of Material Science, vol. 34, no. 1, pp. 1137-1150, 2011, DOI: http://doi.org/10.1007/s12034-011-0134-0

[7] Stutzman, E. P., Feng, P and Bullard, J. W. (2016). Phase analysis of portland cement by combined quantitative X-ray powder diffraction and scanning electron microscopy. Journal of research of national Institute of Standards and Technology, 121(4), 1-61. DOI: http://dx.doi.org/10.6028/jres.121.004.

[8] C. J. Humphreys, "The significance of Bragg's law in electron diffraction and microscopy, and Bragg's second law". Foundation Advances, vol. 69, no. 1, pg. 45-50, 2013, DOI: https://doi.org/10.1107/S0108767312047587

[9] ASTM C 128, "Standard test method for density, relative density (specific gravity), and absorption of fine aggregate". ASTM International, vol. 3, no. 2, pp. 1-6, 2001, DOI: https://doi.org/ 10.1520/C0128-12.1

[10] ASTM C 29, "Standard test method for bulk density (unit weight) and voids in aggregates". ASTM International, vol. 7, no. 4, pp. 1-4, 1997.

[11] ASTM C 56, (1997). "Standard test method for total evaporable moisture content of aggregate by drying". ASTM International, 1997, DOI:

file://C:/Users/user/Downloads/C566\%20(2).PDF

[12] ASTM D 1238, "Test Method for Melt Flow Rates of Thermoplastics by Extrusion Plastometer". ASTM International. 2013 DOI:

https://apandales4.files.wordpress.com/2014/02/d1238370238-1.pdf

[13] G. Farrow, and D. Preston, "Measurement of crystallinity in drawn polyethylene terephthalate fibres by X-ray diffraction". British Journal of Applied Physics, vol. 11, no. 8, 2002, DOI: 10.1088/0508-3443/11/8/310.

[14] V. B, Gupta, A. K. Radhakrishnan and P. K. Chidambareswaran, "Crystal perfection in axially oriented poly(ethylene terephthalate) fibers and films and its dependence on process variables". Journal of Macromolecular
Science, vol. 33, no. 2, pp. 185-207, 1994, DOI: $10.1080 / 00222349408248087$.

[15] M. Vashista, and S. Paul, "Correlation between full width at half maximum (FWHM) of XRD peak with residual stress on ground surfaces". Philosophical Magazine, vol. 92, no. 33, pp. 4194-4204, 2012, DOI: 10.1080/14786435.2012.704429.

[16] I. K Ejiogu, U. Ibeneme, Y. E. Ishidi, O. G. Tenebe, and M. D. Ayo, "Biodegradable hybrid polymer composite reinforced with coconut shell and sweet date seed (Phoenix dactylifera) powder: a physico-mechanical study; part A". Multiscale and Multidisciplinary Modeling, Experiments and Design, vol. 3, pp. 45-51, 2019, DOI: https://doi.org/10.1007/s41939-01900060-3

[17] I. K. Ejiogu, U. Ibeneme, O. G. Tenebe, M. D. Ayo, "Mosunmade Olukemi Ayejagbara (2019). Natural Fibre Reinforced Polymer Composite (NFRPC) from Waste Polypropylene Filled with Coconut Flour". International Journal of Engineering Technology and Sciences (IJETS). vol. 6, no. 2, pg. 50-64, 2019, http://dx.doi.org/10.15282/ijets.6.2.2019.1005

[18] M. A. Gondal, M. N. Siddiqui, "Identification of different kinds of plastics using laser induced breakdown spectroscopy for waste management". J. Environ. Sci. Health Pt A, vol. 42, no. 13, pg. 1989-1997, 2007.

[19] N. V. BHA, and R. R. Deshmukh, "X-ray crystallographic studies of polymeric materials". Indian Journal of Pure and Applied Physics, vol. 40, pp. 361-66, 2002.

[20] M. Colakogu, "Damping and vibration analysis of polyethylene fibre composite under varied temperature". Turkish Journal of Engineering and Environmental Sciences, vol. 30 , no. 2, pp. 351-357, 2006.

[21] D. Dunson, "Characterization of polymers using dynamic mechanical analysis (DMA)". Eurofins Material Scieneces, pp. 1-8, 2017, Retrieved December 3rd, 2020 from https://www.eag.com/wp-content/uploads/2017/09/M-022717Characterization-of-Polymers-using-Dynamic-MechanicalAnalysis.pdf

[22] N. V. Bhatt, and R. R. Deshmukh, "X-ray crystallographic studies of polymeric materials". Indian Journal of pure and Applied Physics, vol. 40, no. 5, pp: 361-366, 2002, DOI: IJPAP 40(5) 361-366.pdf 1 / 6.

[23] N. S. Murthy, S. T. Correale, and H. Minor. "Structure of the amorphous phase in crystallizable polymers". Poly (ethylene terephthalate) Macromolecules 1991 vol. 24, no. 5, pp. 11851189.1991, DOI: 10.1021/ma00005a033.

[24] Z. A. A. Atif, A. M. Mohammed, and N. M Abbass, "Synthesis and characterization of polymer nanocomposites from methyl acrylate and metal chloride and their application". Polym. Bull, vol. 77, pp. 5879-5898, 2020. https://doi.org/10.1007/s00289019-03047-9

[25] A. Elamri, K. Abid, O. Harzallah, A. Lallam. "Characterization of Recycled/ Virgin PET Polymers and their Composites". American Journal of Nano Research and Application. Special Issue: Nanocomposites Coating and Manufacturing. Vol. 3, No. 4-1, pp. 11-16, 2015, doi: 10.11648/j.nano.s.2015030401.13. 